\title{
Thirty years of scientific research on second-generation antipsychotic drugs in Japan: A bibliometric analysis"
}

\author{
Francisco López-Muñoz ${ }^{1,2 \#, ~ N a o t a k a ~ S h i n f u k u ~}{ }^{3}$, Winston W. Shen ${ }^{4}$, Raquel Moreno ${ }^{1}$, \\ Juan D. Molina ${ }^{1,5}$, Gabriel Rubio $^{6}$, Lorena Huelves ${ }^{1}$, Concha Noriega ${ }^{1}$, Miguel A. Pérez-Nieto ${ }^{1}$, \\ Cecilio Álamo
}

${ }^{1}$ Faculty of Health Sciences, Camilo José Cela University, Madrid, Spain

${ }^{2}$ Department of Pharmacology, University of Alcalá, Madrid, Spain

${ }^{3}$ School of Human Sciences, Seinan Gakuin University, Fukuoka, Japan

${ }^{4}$ Department of Psychiatry, Taipei Medical University, Wan Fang Medical Center, Taipei, Taiwan

${ }^{5}$ Acute Inpatients Unit, Dr. R. Lafora Psychiatric Hospital, Madrid, Spain

${ }^{6}$ Department of Psychiatry, "Doce de Octubre" University Hospital, Complutense University, Madrid, Spain

Email: ${ }^{*}$ francisco.lopez.munoz@gmail.com

Received 25 October 2012; revised 27 November 2012; accepted 5 December 2012

\begin{abstract}
Aims: Research on second-generation antipsychotic drugs (SGAs) has experienced great development in last decades. We did a bibliometric study on the scientific publications on SGAs in Japan. Methods: With the EMBASE and MEDLINE databases, we chose papers published from Japan with SGA descriptors. Price's law and Bradford's law has been used as bibliometric indicators for quantitating production and dispersion, respectively, of published papers on SGAs. We also calculated the participation index of different countries, and correlated those bibliometric data with some social and health data from Japan (such as total per capita expenditure on health and gross domestic expenditure on research and development). Results: A sum of 669 original documents were published from Japan from 1982 to 2011. Those results fulfilled Price's law, with scientific production on SGAs showing exponential growth (correlation coefficient $r=\mathbf{0 . 9 2 6 1}$, as against an $r=$ 0.8709 after linear adjustment). The most studied SGAs in Japan were risperidone $(n=192)$, aripiprazole $(n=109)$, and olanzapine $(n=106)$. Division of documents into Bradford zones yielded a nucleus occupied exclusively by the Progress in Neuro-Psychopharmacology and Biological Psychiatry (49 articles). Those publications were in 157 different journals. Seven of the first 10 frequently used journals had an impact factor of being greater than 3. Conclusions: The SGA publications in Japan have been through exponential growth over the studied period,
\end{abstract}

*The authors declare no potential conflict of interest, including financial support, for the current study.

${ }^{\#}$ Corresponding author. without evidence of reaching a saturation point.

Keywords: Second-Generation Antipsychotics; Atypical Antipsychotics; Bibliometry; Schizophrenia; Bipolar Disorder; Japan

\section{INTRODUCTION}

The main pillars for treating schizophrenia during the last 60 years have been antipsychotic drugs, after the clinical introduction of chlorpromazine [1]. The first drugs, called first-generation (classical or typical) antipsychotic drugs (FGAs), showed a great efficacy at reducing positive symptoms (hallucinations, delusion, etc.) of schizophrenia. But their main limitations are extrapyramidal symptoms (EPS). After the re-introduction in the United States of clozapine, an antipsychotic drug marketed in the 1960 s, later withdrawn due to its druginduced agranulocytosis [2], the research expectations changed dramatically. Apart from causing few EPS, this agent showed efficacy in both positive and negative symptoms as well as in patients who are refractory to treatment with other FGAs [3]. Clozapine opened the door to the socalled second-generation (atypical) antipsychotic drugs (SGAs) [4] with risperidone's introduction in 1993.

The advances achieved from antipsychotic drugs in the past 30 years have been incredibly important, with the advent of many SGAs as shown in Table 1. The Japanese pharmaceutical companies (Dainippon Sumitomo Pharma, Otsuka Pharmaceutical, Fujisawa Pharmaceutical, etc.) have played relevant roles. These SGAs have notably improved the quality of life of psychotic patients and have contributed to weakening the stigmatization [5].

In the US, SGAs were initially introduced in 1993, and were later also licensed for treating bipolar disorder in 
Table 1. Clinical development of second-generation antipsychotic drugs.

\begin{tabular}{cccc}
\hline & Company & \multicolumn{2}{c}{ Launch } \\
Clozapine & Wander Laboratories & $1972^{*}$ & Switzerland \\
Zotepine & Fujisawa & $1982^{* *}$ & Japan \\
Amisulpride & Synthelabo & 1986 & Portugal \\
Risperidone & Johnson \& Johnson & 1993 & UK/Canada \\
Sertindole & Abbott Laboratories & $1996^{* * *}$ & UK \\
Olanzapine & Eli Lilly & 1996 & USA/UK \\
Quetiapine & AstraZeneca & 1997 & USA/UK \\
Ziprasidone & Pfizer & 2001 & USA \\
Perospirone & Dainippon Sumitomo Pharma & 2001 & Japan \\
Aripiprazole & Otsuka/Bristol-Myers Squibb & 2002 & USA \\
Paliperidone & Janssen Pharmaceutica & 2007 & USA \\
Blonanserin & Dainippon Sumitomo Pharma & 2008 & Japan \\
Asenapine & Schering-Plough & 2009 & USA \\
Iloperidone & Novartis AG & 2009 & USA \\
Lurasidone & Dainippon Sumitomo Pharma & 2011 & USA \\
\hline
\end{tabular}

*Reintroduced in 1990 in USA and UK after being withdrawn from the market in $1975 ;{ }^{* *}$ Commercialized by Astellas in Germany in 1990; ${ }^{* * *}$ Marketing authorization was suspended by the European Medicines Agency (EMA) in 1998 and the drug was withdrawn from the market. In 2002, based on new data, the EMA suggested that sertindole could be reintroduced for restricted use, and with extensive ECG monitoring requirement.

2003. SGA research has equally advanced considerably in Japan although only olanzapine and aripiprazole werefirst approved in 2012 for treating bipolar disorder there. This development in Japan has caused a considerable increase in the amount of SGA scientific papers.

Japan has a great tradition in the care of patients with schizophrenia [6]. Japan has the biggest number of psychiatric beds in the world (with 1600 psychiatric hospitals). In 1980, more than 300,000 mentally ill stayed at psychiatric hospitals in Japan; out of them, more than 100,000 patients had stayed over 10 years [6]. About $80 \%$ of them were diagnosed as schizophrenia [6]. In addition, political, social and economic conditions of Japan have greatly influenced the development of psychiatry in Japan during last three decades.

With bibliometric studies, our group has studied the evolution of scientific literature in psychiatry by specific research groups, on different psychiatric disorders, on aspects related to the discipline, and on specific therapeutic tools in psychopharmacology [7-11]. Here, we specifically did this bibliometric study on SGA publications in Japan.

\section{METHODS}

Due to space limitation, we just stated key concepts of methods briefly here. Readers should refer to other articles [7-11] for more information in methodology in this study.

In this study, we did not seek the study approval at institution's ethics committee for clinical investigation because all the data used in this study were based on secondary published materials. We did not do any direct experiments on human subjects, therefore, it conforms to the provisions of the Declaration of Helsinki (as revised in Edinburgh 2000).

\subsection{Data Sources}

The databases used in this bibliometric study were MEDLINE (Index Medicus, US National Library of Medicine, Bethesda, Maryland, USA) and Excerpta Medica (Elsevier Science Publishers, Amsterdam, the Netherlands). Both are in EMBASE Biomedical Answer web (Elsevier B.V.).

With remote downloading techniques, we chose all 1982-2011 published documents, containing, in the author's address (AD) section the descriptor Japan, and in the title (TI) section, the descriptors atypic ${ }^{*}$ (atypical) antipsychotic ${ }^{*}$ (antipsychotical), second-generation antipsychotic $^{*}$ (antipsychotical), clozapine, risperidone, olanzapine, ziprasidone, quetiapine, sertindole, aripiprazole, paliperidone, amisulpride, zotepine, asenapine, iloperidone, lurasidone, perospirone and blonanserin. We included all the original articles, brief articles, reviews, editorials, letters-to-the-editor, etc., and all duplicated papers were omitted.

With manual coding after studying the title and/or abstracts of the articles, we divided those papers into four groups: "experimental pharmacology", "clinical efficacy", "tolerance and/or safety" and "not specified group".

\subsection{Bibliometric Indicators}

\subsubsection{Price's Law}

Price's law [12] reflects a fundamental aspect of scientific production, which is its exponential growth. To assess whether the growth of scientific production in SGAs on Japan follows Price's law of exponential growth, we made a linear adjustment of the data obtained, according to the equation $y=2.4684 x-16.042$, and another adjustment to an exponential curve, according to the equation $y=1.534 \mathrm{e}^{0.1313 x}$.

\subsubsection{Bradford's Law}

To show the dispersion of the scientific literature in a particular discipline, Bradford proposed a model of concentric zones of productivity (Bradford zones) with decreasing density of information [13]. Each zone would 
contain a similar number of documents, but the number of journals in which these are published would increase on passing from one zone to another. This model permits identification of the journals most widely used or with greatest weight in a given field of scientific production.

\subsubsection{Impact factor}

We used the impact factor (IF) as an indicator of the publications' repercussion. This indicator developed by the Institute for Scientific Information (Philadelphia, Pennsylvania, USA), is published annually in the Journal Citation Reports (JCR) section of the Science Citation Index $(S C I)$. We used the IF data of 2011 published in the $J C R$ of 2012 .

\subsubsection{Participation index}

Another indicator included in the present analysis is the national participation index (PI) of Japan for overall scientific production (the ratio of the number of documents generated by Japan and the total number of documents on this topic). This PI has also been compared with global PI in biomedical and health sciences (as well as for Psychiatry and Neurology area in particular). Likewise, the PI has been correlated with some health data, such as total per capita expenditure on health and gross domestic expenditure on research and development.

The PI has also been correlated with the corresponding PI for the world's 15 most productive countries during the period 1982-2011. Its health data were obtained from Organisation for Economic Co-operation and Development (OECD) Health Division [14], and WHO Department of Health Statistics and Informatics [15].

\section{RESULTS}

From 1982 to 2011, we got 669 original Japanese SGA papers: 192 were on risperidone, 109 aripiprazole, 106 olanzapine, 60 perospirone, 58 clozapine, 47 zotepine, 33 quetiapine, 26 blonanserin, 17 lurasidone, 6 sertindole, 5 ziprasidone, and 2 paliperidone. We did not find any paper on asenapine, iloperidone and amisulpride (perospirone is only available on the market in Japan, blonanserin is available in Japan and South Korea, and amisulpride is not available in Japan.)

As shown in Figure 1, over the last 30 years there had a marked increase in the number of SGA papers from Japan. The mathematical adjustment to an exponential curve permitted us to get a $14.22 \%$ of variance unexplained by this fitting, contrariwise, the linear adjustment of the measured values gave a percentage of unexplained variance of $24.14 \%$, suggesting that the postulated Price's law was fulfilled. Figure 2 depicts the cumulative growth in total scientific production on SGAs in Japan in each five-year period over the previous one.

We applied the Bradford's model to analyse SGA papers, and found that the mean number of articles per Bradford zone, without the last zone, whose accuracy

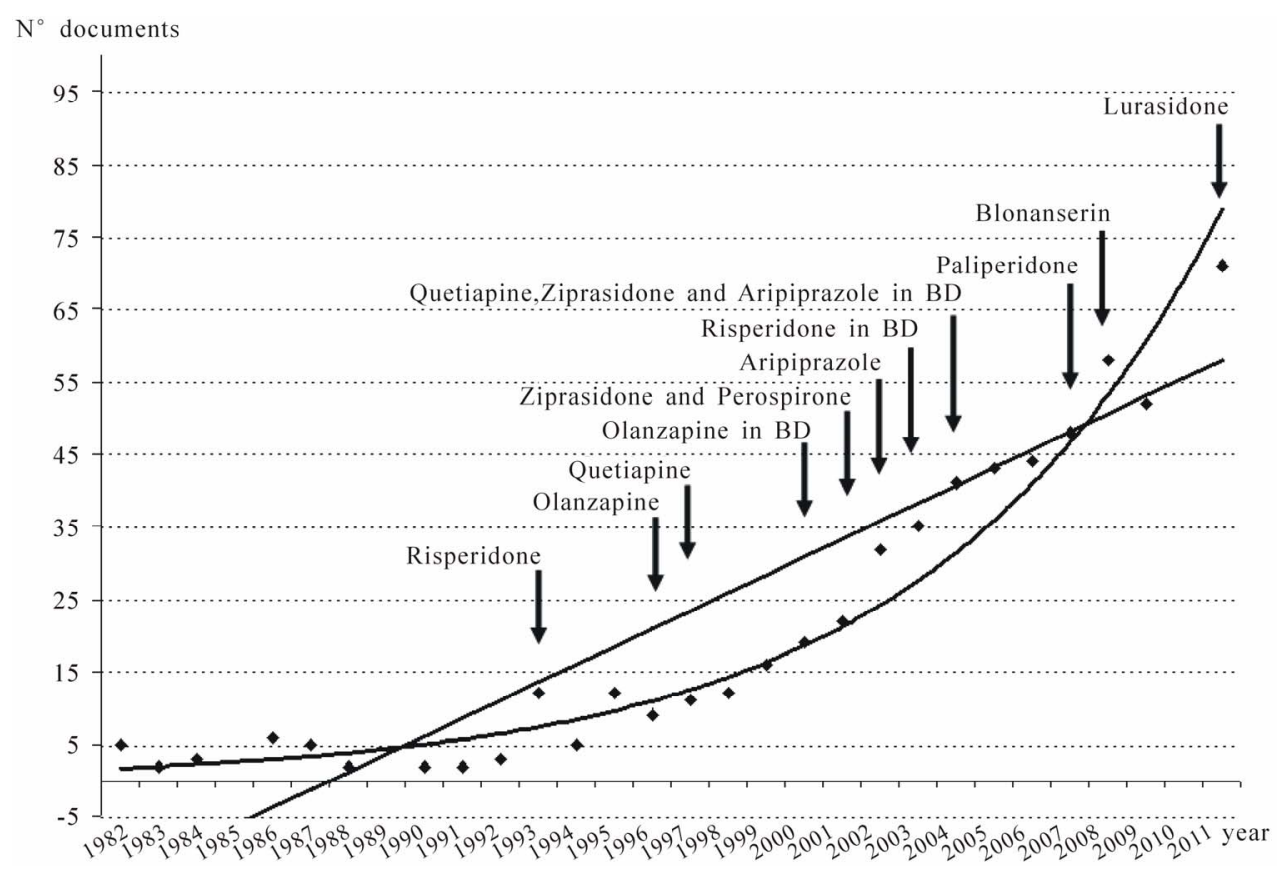

Figure 1. Growth of scientific production on second generation antipsychotic drugs (SGAs) in Japan and international licensing of different drugs. A linear adjustment of the data was carried out, and a fitting to an exponential curve was found, to follow Price's law of exponential growth for SGA publication production. Linear adjustment: $y=2.4684 x-16.042\left(r^{2}=0.7586\right)$. Exponential adjustment: $y=1.534 \mathrm{e}^{0.1313 x}\left(r^{2}=0.8578\right)$. BD, bipolar disorder. 


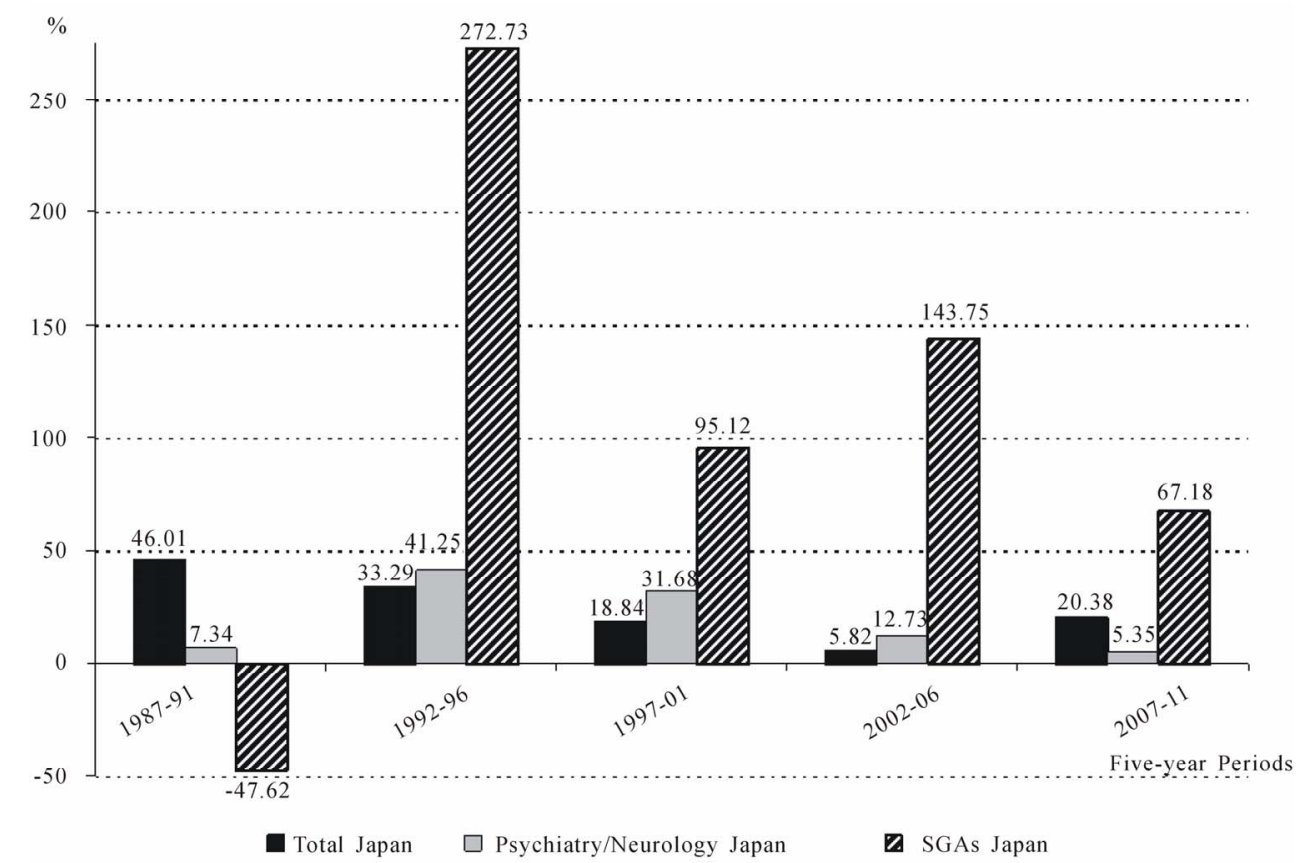

Figure 2. Cumulative growth by five-year periods of scientific production on total Japan productivity in biomedicine and health sciences, Psychiatry and Neurology area, and second-generation antipsychotic drugs (SGAs) in Japan. Data from each five-year period are referred to evolution over the previous period. The period of reference is 1982-1986. Data are expressed in percentages. Notable in this respect is the rate of accumulated growth (272.73\%) of SGAs in the period 1992-1996.

was obviously lower, being 51.46. The nucleus or first zone would be made up exclusively of the Progress in Neuro-Psychopharmacology and Biological Psychiatry $(\mathrm{n}=49)$ and the second zone of Psychiatry and Clinical Neurosciences $(n=43)$, the official English journal of Japanese Society of Psychiatry and Neurology (JSPN). The rest of the journals analyzed are included in zones 3 to 14 . A total of 157 different journals were involved in those papers. Table 2 lists top 10 most published journals which accounted for $40.81 \%$ of all the papers in this study database. Those journals most extensively used for the diffusion of SGA papers have high IFs ( 7 of them have an IF $>3$, and 5 an IF $>4$ ).

Manually classifying articles, we found that $40.06 \%$ of them belonged to the "experimental pharmacology" group, $38.10 \%$ to the "clinical efficacy" group, $17.17 \%$ to the "tolerance and safety" group, and $4.67 \%$ to the "not specified" group (mainly, reviews on different SGAs).

Figure 3 depicts that the countries generating research on SGAs, is the US, whose PI is 32.1 , followed by the United Kingdom, Germany, Canada, Italy and Spain. But if we consider the productivity of these countries in this area in relation to their overall production in the field of Psychiatry and Neurology, only 4 (Belgium, India, Spain and Sweden) of the 15 largest producers in biomedicine and health sciences from 1982 to 2011, devote a higher percentage of attention to the study of SGAs. Japan occupied the last position of these 15 countries.
Table 2. The 10 journals with highest number of publications on second-generation antipsychotic drugs by Japanese authors.

\begin{tabular}{|c|c|c|c|}
\hline Journal & No. of documents & PI & IF $^{*}$ \\
\hline $\begin{array}{c}\text { Progress in } \\
\text { Neuro-Psychopharmacology } \\
\text { and Biological Psychiatry }\end{array}$ & 49 & 7.32 & 3.247 \\
\hline $\begin{array}{l}\text { Psychiatry and Clinical } \\
\text { Neurosciences }\end{array}$ & 43 & 6.43 & 2.133 \\
\hline $\begin{array}{l}\text { International Journal of } \\
\text { Neuropsychopharmacology }\end{array}$ & 34 & 5.08 & 4.578 \\
\hline Psychopharmacology & 28 & 4.19 & 4.077 \\
\hline $\begin{array}{l}\text { European Journal of } \\
\text { Pharmacology }\end{array}$ & 28 & 4.19 & 2.516 \\
\hline $\begin{array}{l}\text { Journal of Clinical } \\
\text { Psychopharmacology }\end{array}$ & 21 & 3.14 & 4.098 \\
\hline $\begin{array}{l}\text { Human Psychopharmacology } \\
\text { Clinical and Experimental }\end{array}$ & 21 & 3.14 & 2.476 \\
\hline Schizophrenia Research & 17 & 2.54 & 4.748 \\
\hline Journal of Clinical Psychiatry & 16 & 2.39 & 5.664 \\
\hline $\begin{array}{c}\text { European } \\
\text { Neuropsychopharmacology }\end{array}$ & 16 & 2.39 & 4.046 \\
\hline
\end{tabular}

PI, participation index; IF, impact factor (2011); 'Journal Citation Report, 2011 (JCR, 2012).

In the analysis of the correlation between PI and the per capita health expenditure of each of the countries with the highest scientific production in health sciences, the distribution obtained is quite similar, except for China and India (Figure 4). But Japan occupied the se- 


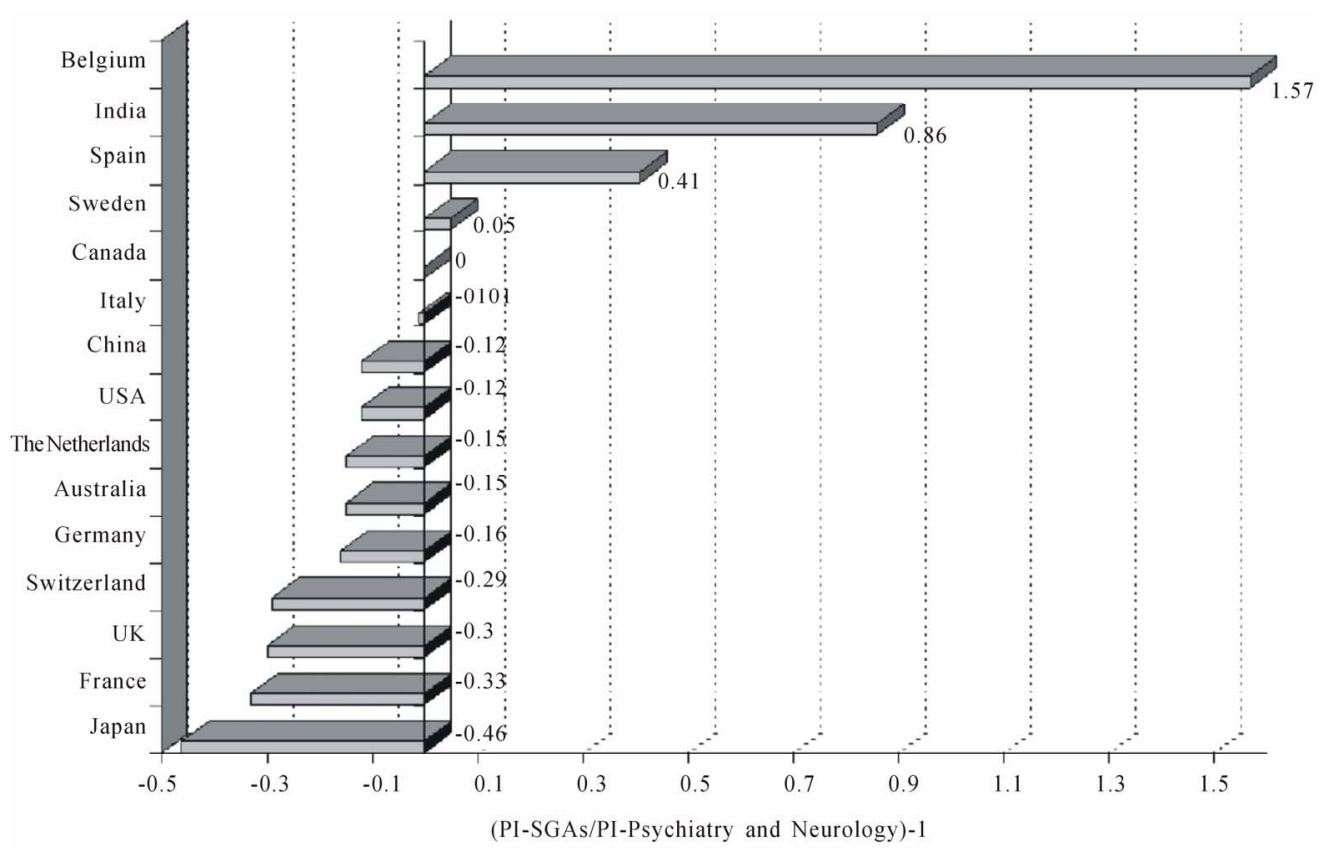

Figure 3. Relationship between production of scientific literature on second-generation antipsychotic drugs and total production in the field of Psychiatry and Neurology in the world's 15 most productive countries in biomedicine and health sciences. PI, participation index; SGAs, second-generation antipsychotic drugs.

(PI/Per capita Health Expenditure) $\times 1000$

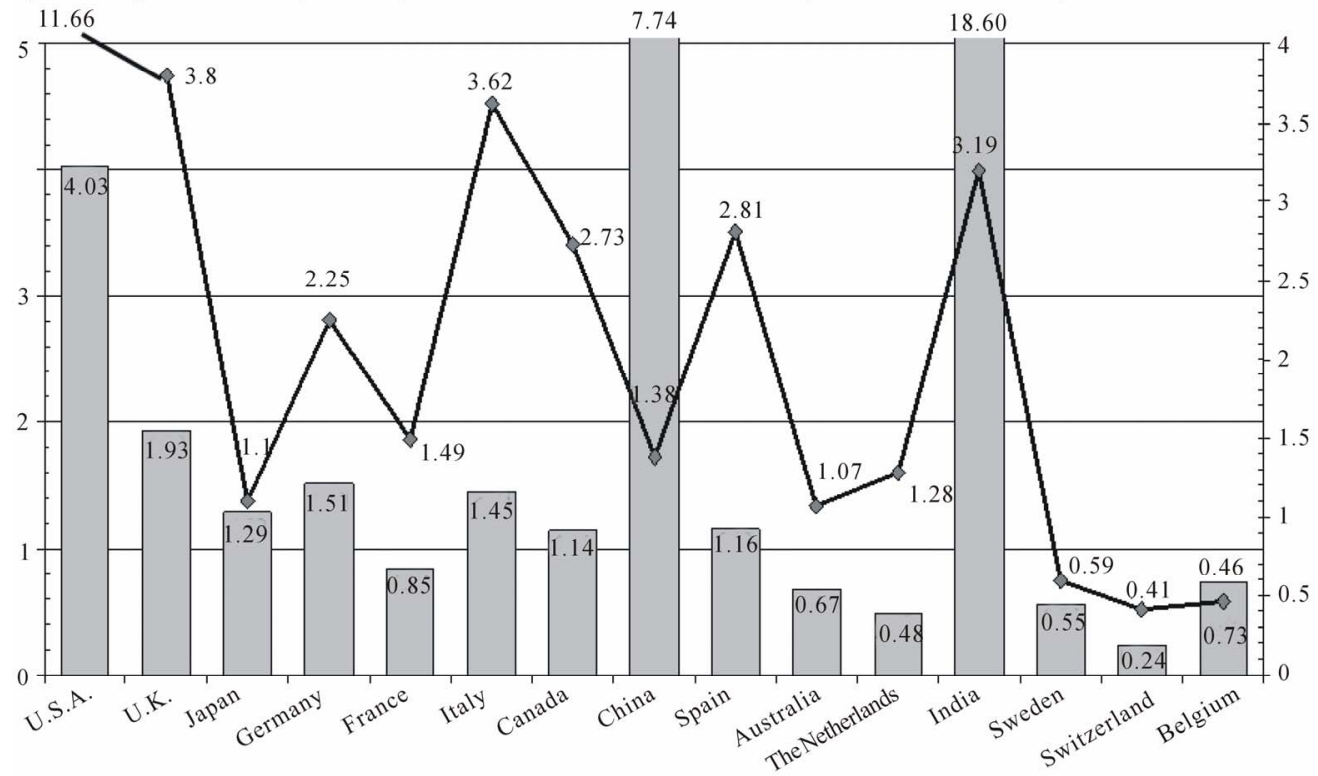

(PI/Gross Domestic Expenditure on R\&D

$\square(\mathrm{PI} / \mathrm{Per}$ capita Health Expenditure $) \times 1000 \prec(\mathrm{PI} /$ Gross Domestic Expenditure on R\&D

Figure 4. Relationship between production of scientific literature on second-generation antipsychotic drugs and per capita health expenditure and gross domestic expenditure on research and development, in the world's 15 most productive countries in biomedicine and health sciences. PI, participation index; R $\& \mathrm{D}$, research and development. Total health expenditure per capita personal purchasing power (PPP) US \$ (data from Organisation for Economic and Co-operative Development (OECD) 2009) [14]. Japan and Australia; Data 2008; China and India: Total health expenditure per capita PPP Int \$ (data 2008) [15]; Gross Domestic Expenditure on R\&D (\%); Data OECD 2010, except USA and Japan (data 2009), Switzerland and The Netherlands (data 2008), China (data 2007) and India (data 2004). 
venth position in this ranking.

Top ten most productive institutions in SGA papers in Japan were (A) Department of Neuropsychiatry, Graduate School of Medicine, Hirosaki Graduate University, Hirosaki, Aomori Ken $(n=39)$; (B) University of Occupational and Environmental Health, Fukuoka (34); (C) Graduate School of Medicine, Hokkaido University, Sapporo (24); (D) Otsuka Pharmaceutical Co. Ltd., Tokushima (24); (E) Department of Psychiatry and Neurosciences, Graduate School of Biomedical Sciences, Hiroshima University, Hiroshima (17); (F) Osaka Medical College, Osaka (16); (G) Dainippon Sumitomo Pharma Co., Osaka (16); (H) Niigata University Graduate School of Medical and Dental Sciences, Niigata (15); (I) Keio University School of Medicine, Tokyo (15); and (J) Kansai Medical University, Osaka (13). This listing is based on the corresponding author's affiliated institutions in the $\mathrm{AD}$ field in the EMBASE Biomedical Answer web database.

\section{DISCUSSION}

The design of this study allows us to make a global assessment of the growth of scientific SGA literature in Japan. The paper number has been through an exponenttial growth over the last 30 years, and especially after 2000, without evidence of reaching saturation postulated by Price's law [12]. As shown in Figure 1, this date coincides with the approval for marketing by the US Food and Drug Administration (FDA) and other international regulatory agencies for olanzapine in treating manic episodes. Since 2004, other SGAs such as risperidone, quetiapine, ziprasidone, aripiprazole, and asenapine, etc., have been also approved for treating manic episodes, and olanzapine and aripiprazole for relapse prevention in patients with bipolar disorder [16]. Quetiapine is indicated as monotherapy for the acute treatment of depresssive episodes associated with bipolar disorder, and olanzapine-fluoxetine combination for treating treatmentresistant major depressive disorder. Also aripiprazole was approved in 2007 by the US FDA for treating treatment-resistant major depression as an add-on to an antidepressant [16]. Finally, SGAs are also commonly used (and studied) in many off-label indications, such as substance-induced psychosis, agitation symptoms, tics, substance abuse disorders, etc.

Prestigious journals such as Journal of Clinical Psychiatry (IF = 5.664), Schizophrenia Research (IF = 4.748), International Journal of Neuropsychopharmacology (IF = 4.578), or Journal of Clinical Psychopharmacology (IF = 4.098) publish SGA articles from Japan. This fact indicates both clinical and social relevance that Japan has acquired in recent years. Among those 10 journals most widely used by Japanese authors listed in Table 2, 7 are in the ranking of the most relevant in the field of Psychiatry (IF $>3.00$ ).

Although there are no specific data on SGAs published in this field, some authors, also applying bibliometric tools, have reported the research activity in the field of schizophrenia as superior to that of other fields of psychiatry [17]. These authors also suggest that the attraction of research on schizophrenia may have been positively affected by the clinical perception of the greater seriousness of the illness compared to other psychiatric illnesses. Moreover, Theander and Wetterberg reported that the number of references on schizophrenia in MEDLINE has followed the general increase of medical publications, which accounts for $0.42 \%$ compared to the total medical literature in the period studied [18].

To the PI of the different countries in scientific production on SGAs, the US and the UK, head the ranking of producer countries, and generate over one third of total scientific production in this field $(36.7 \%)$. The fact that in these two countries are home to the pharmaceutical companies responsible for the development of SGAs (olanzapine, Eli Lilly; risperidone and paliperidone, Janssen Pharmaceutica; quetiapine, AstraZeneca; ziprasidone, Pfizer; aripiprazole, Bristol-Myers Squibb/Otsuka Pharmaceutical) may help explain this high PI. But strikingly, Japan is ranked as the sixth producer in this field, despite being responsible for the development of five SGAs (zotepine, perospirone, aripiprazole, blonanserin, and lurasidone) and the great importance of mental health, particularly in the area of schizophrenia. Japan was the first and the only Asian country in 2002 to rename schizophrenia into togo-shicchou-sho, in attempt to de-stigmatize those with this disorder [6]. This kind of effort made by the psychiatrists and lay public in Japan is not seen elsewhere in the world.

Figure 3 shows how some countries, such as Belgium, India, or Spain, sit near the top of the ranking for SGA paper production with respect its general productivity in the Psychiatry \& Neurology discipline, reflecting the special interest of these countries in SGA research. In a similar study, Taiwan which has only about one-fifth (23 million) of the population of Japan, had produced 359 papers from 1993 to 2011, being published in comparably prestigious journals [11]. Contrariwise, the lower relative interest in these drugs of countries such as France, the UK, Switzerland, and specially Japan (Figure 3).

We would like to offer three reasons for Japanese productivity SGA publications as shown in Figure 3. First, the reason can be illustrated in a historical case story of carbamazepine [19]. Takezaki and Hanaoka of Totorri prefecture in 1971 were the first two psychiatrists in the world to discover the use of carbamazapine in treating manic patients, but it took a long time to spread this scientific contribution outside of Japan because the original article was published in Senshin Igaku (Folio) [20]. 
Second, another reason could have been the delay in Japan of licensing new drugs or new indications [21], especially in neulological [22] and psychiatric [23] medications. Apart from sildenafil, Japanese regulatory process was notoriously slow. For example, the first selective serotonin reuptake inhibitor (SSRI), fluvoxamine, was marketed in Japan in 1999, and second SSRI, paroxetine, in $2001[23,24]$. Japanese regulatory authority released the marketing licence of clozapine in 2009, and authorized olanzapine and aripiprazole for the indication to treat acute mania in 2012 [23]. Shimazawa et al. found that of the 23 psychiatric drugs being all approved in the UK and the USA, only 13 of them were introduced in Japan between September 2000 and July 2011; that none of their development strategies adopted the International Conference on Harmonisation E5 guideline on simultaneous development of drugs on a global scale; and that the median review time (from approval application to approval) of these studied 13 drugs in Japan was 23 months which was considerably longer than those of European Medicines Agency and the US FDA (13.5 and 10.0 months, respectively) [23]. They further lamented that the $10-13$ months difference in review time can not explain the overall 87- and 51-month delay in Japan after approval in the UK or in the USA [23]. Usually, the patients in South Korea and Taiwan can get the needed SGAs for their patients in 2 - 3 years following the approval of the US FDA. But the improvement of this delay of an SGA would be improved as evidence of the amount of newly published papers from the manufacturers of aripiprazole and lurasidone. And third, Japan had produced higher percentage of SGA papers in basic research $(40.06 \%)$ than clinical papers $(38.30 \%)$ comparing with other countries/areas in the area such as Taiwan $(29.53 \%$ and $40.11 \%$, respectively) [11]. The productiveity of basic research by Japanese psychiatrists has always been admired by counterparts in Asian countries. But executing clinical drug trials and implementing institutional review board for protecting human research subjects in Japan have recently become popular. These phenomena indicate that remarkable improvement in the productivity of clinical research papers in Japan would be expected in the near future.

The correlation of scientific production in SGAs with the per capita health expenditure of each country (Figure 4), offers us a parallel view of this phenomenon; in general, there is confirmation of the notion that the higher the spending on health, the greater the research production. It is striking, however, to observe the low ratios of countries such as Switzerland, Sweden or Netherlands. The correlation analysis between scientific production in SGAs and the gross domestic expenditure on $\mathrm{R} \& \mathrm{D}$ located to Japan at the eleventh position.

We have offered a picture of the representativeness and evolution of international research on SGAs in Japan, observing the parameters of quality and dissemination most commonly used at an international level. Besides the differences in antipsychotic prescribing patterns between Japan and other countries $[25,26]$, we also found in this study that the research paper productivity on SGAs was different from Japan to other Asian countries/areas such as Taiwan [11]. But we trust that research in this field will possibly continue to grow in the coming years, bearing in mind that the ideal antipsychotic drug has not yet been found [5] and that etiopathogeny of schizophrenia is still mostly unknown.

\subsection{Limitations}

First, we might have excluded those papers on SGAs if the authors have not put our study inclusion descriptors in the titles or as key words. Moreover, local journals that are not indexed in MEDLINE and Excerpta Medica during the study period, and those contributions from Japanese investigators at scientific conferences and meetings were also not included in our current study.

Second, in the AD section using the descriptor "Japan," we included those papers with authors specifying "Japan" in their addresses only. We did not count those papers as Japan papers if the contributor authors from Japan had not put their Japanese addresses.

Third, the use of the SCI impact factor to determine the merit or quality of scientific contributions is still debatable. The citation count applied in calculating the impact factor may not directly reflect the importance or quality of one study; on the contrary, it may only represent the topic of a given study being "more fashionable", or even "not yet mature" and/or "in need of more studies." This might explain why most universities of the US, unlike those in Europe and in Asia, do not usually use impact factor to evaluate the academic outputs of their faculty members.

\section{CONCLUSION}

The SGA publications in Japan have been through exponential growth over the studied period, without evidence of reaching a saturation point.

\section{ACKNOWLEDGEMENTS}

This study was supported by a grant (UCJC 2012-01) of the Camilo José Cela University (I Convocatoria de Ayudas a la Investigación Competitiva).

\section{REFERENCES}

[1] López-Muñoz, F., Alamo, C., Cuenca, E., Shen, W.W., Clervoy, P. and Rubio, G. (2005) History of the discovery and clinical introduction of chlorpromazine. Annals of 
Clinical Psychiatry, 17, 113-135. doi:10.1080/10401230591002002

[2] Shen, W.W. (1999) A history of antipsychotic drug development. Comprehensive Psychiatry, 40, 407-414. doi:10.1016/S0010-440X(99)90082-2

[3] Kane, J., Honigfeld, G., Singer, J. and Meltzer, H. (1988) Clozapine for the treatment-resistant schizophrenic. Archives of General Psychiatry, 45, 780-796.

[4] Hippius, H. (1999) A historical perspective of clozapine. Journal of Clinical Psychiatry, 60, 22-23.

[5] López-Muñoz, F. and Álamo, C. (2011) Neurobiological background for the development of new drugs in schizophrenia. Clinical Neuropharmacology, 34, 111-126. doi:10.1097/WNF.0b013e318215c2f7

[6] Shinfuku, N. (2012) What are happening in the mental health system in Japan: Some observations. Taiwanese Journal of Psychiatry, 26, 70-76.

[7] López-Muñoz, F., Vieta, E., Rubio, G., García-García, P. and Alamo, C. (2006) Bipolar disorder as an emerging pathology in the scientific literature: A bibliometric approach. Journal of Affective Disorders, 92, 161-170. doi:10.1016/j.jad.2006.02.006

[8] López-Muñoz, F., Álamo, C., Quintero-Gutiérrez, F.J. and García-García, P. (2008) A bibliometric study of international scientific productivity in attention-deficit hyperactivity disorder covering the period 1980-2005. European Child and Adolescent Psychiatry, 17, 381-391. doi:10.1007/s00787-008-0680-1

[9] López-Muñoz, F., García-García, P., Sáiz-Ruiz, J., Mezzich, J.E., Rubio, G., Vieta, E. and Álamo, C. (2008) A bibliometric study of the use of the classification and diagnostic systems in psychiatry over the last 25 years. Psychopathology, 41, 214-225. doi:10.1159/000125555

[10] López-Muñoz, F., Alamo, C., Rubio, G., García-García, P., Martín-Agueda, B. and Cuenca, E. (2003) Bibliometric analysis of biomedical publications on SSRIs during the period 1980-2000. Depression \& Anxiety, 18, 95-103. doi:10.1002/da.10121

[11] López-Muñoz, F., Shen, W.W., Moreno, R., Molina, J.D., Noriega, C., Pérez-Nieto, M.A., Rubio, G. and Álamo, C. (2012) International scientific productivity on secondgeneration antipsychotic drugs in Taiwan: A bibliometric study. Taiwanese Journal of Psychiatry, 26, 114-129.

[12] Price, D.J.S. (1963) Little science, big science. Columbia University Press, New York.

[13] Bradford, S.C. (1948) Documentation. Crosby Lockwood, London.

[14] OECD Health Division (2011) OECD Health Data 2011-Frequently Requested Data. OECD, Paris.

[15] World Health Organisation Department of Health Statistics and Informatics (2011) World Health Statistics 2011.
WHO, Geneva.

[16] Shen, W.W. (2011) Clinical Psychopharmacology for the 21 Century, the Third Edition (in Mandarin). Ho-Chi Publishing Company, Taipei.

[17] Clement, S., Singh, S., and Burns, T. (2003) Status of bipolar disorder research. British Journal of Psychiatry, 182, 148-152. doi:10.1192/bjp.182.2.148

[18] Theander, S.S. and Wetterberg, L. (2010) Schizophrenia in Medline 1950-2006: A bibliometric investigation. Schizophrenia Research, 118, 279-284. doi:10.1016/j.schres.2009.05.013

[19] Shen, W.W., López-Muñoz, F. and Alamo, C. (2006) Acido valproico y carbamazepina en el tratamiento del trastorno bipolar: Desarrollo histórico. In: López-Muñoz, F. and Álamo, C., Eds., Historia de la Psicofarmacología, Médica Panamericana, Madrid, 2, 771-782.

[20] Takezaki, H. and Hanaoka, M. (1971) The use of carbamazepine (Tegretol) in the controlod manic-depressive psychosis and other manic, depressive states. Seishin Igaku (Folia Psychiatry Neurology) (in Japanese), 13, 173182.

[21] Hirai, Y., Yamanaka, Y., Kusama, M., Ishibashi, T., Sugiyama, Y. and Ono, S. (2012) Analysis of the success rates of new drug development in Japan and the lag behind the US. Health Policy, 104, 241-246. doi:10.1016/j.healthpol.2011.11.008

[22] Shimazawa, R. and Ikeda, M. (2011) Delays in neurological drug development in Japan. Internal Medicine, 50, 1565-1568. doi:10.2169/internalmedicine.50.5061

[23] Shimazawa, R., Kusumi, I. and Ikeda, M. (2012) Delays in psychiatric drug development in Japan. Journal of Clinical Pharmacy and Therapeutics, 37, 348-351. doi:10.1111/j.1365-2710.2011.01311.x

[24] Tajima, O. (2001) Mental health care in Japan: Recognition and treatment of depression and anxiety disorders. Journal of Clinical Psychiatry, 62, 44.

[25] Sim, K., Su, A., Fujii, S., Chong, M.Y., Ungvari, G.S., Si, T., Chung, E.K., Tsang, H.Y., Chan, Y. H., Heckers, S., Shinfuku, N. and Tan, C.H. (2004) Antipsychotic polypharmacy in patients with schizophrenia: A multicentre comparative study in East Asia. British Journal of Clinical Pharmacology, 58, 178-183. doi:10.1111/j.1365-2125.2004.02102.x

[26] Sim, K., Chuan, H., Fujii, S., Yang, S.I., Chong, M.Y., Ungvari, G.S., Si, T., He, Y.L., Chung, E.K., Chan, Y.H., Shinfuku, N., Kua, E.H., Tan, C.H. and Sartorius, N. (2009) High-dose antipsychotic use in schizophrenia: A comparison between the 2001 and 2004 Research on East Asia Psychotropic Prescription (REAP) studies. British Journal of Clinical Pharmacology, 67, 110-117. doi:10.1111/j.1365-2125.2008.03304.x 